\title{
Effect of persimmon leaves (Diospyros kaki) on goblet cell density and inflammation in experimental dry eye model
}

Kyung-A Kim ${ }^{1,2}$, Chung Hyun Lee ${ }^{3}$, Tae Kyeom Kang ${ }^{1}$, Sung Jae Yang ${ }^{4}$, Chang Yong Lee ${ }^{5}$, Wook-Bin Lee ${ }^{1 *}$ and Sang Hoon Jung ${ }^{1,2,5^{*}}$

\begin{abstract}
The efficacy of ethanol extract of Diospyros kaki (EEDK) on dry eye (DE) was determined using an experimental mouse model. Experimental groups included three treated with various amounts of EEDK and one treated with omega-3 for 2 weeks. Damage to the ocular surface was evaluated, and the presence of conjunctival goblet cells was determined. Moreover, the inflammatory response was analyzed via RT-PCR analysis and a reporter gene assay. Fluorescein staining intensity decreased in the EEDK treatment group, and goblet cell density increased significantly in a dose-dependent manner. Pro-inflammatory cytokines were upregulated in human corneal epithelial cells treated with Pam3Cys-Ser(Lys)-4. However, pro-inflammatory cytokines were downregulated at the mRNA level upon treatment with EEDK. Furthermore, EEDK regulated Pam3CSK4-induced gene expression through interferon regulatory factors. EEDK effectively improves the conjunctival goblet cell density and reduces the inflammatory response by reducing interferon regulatory factor activation downstream of Toll-like receptors in DE. Therefore, EEDK could be beneficial agents for preventing and treating DE.
\end{abstract}

Keywords: Dry eye, Conjunctival goblet cells, Inflammatory response, Pro-inflammatory cytokines, Diospyros kaki

\section{Introduction}

Dry eye (DE) is one of the common causes of visual impairment. It is a disease caused by several factors on the surface of the eye and is characterized by loss of homeostasis of the tear film [1]. Increased osmotic pressure of the tear film and inflammation of the ocular surface induce DE. Patients with DE have various symptoms such as visual discomfort, ocular pain, redness, sensation of a foreign body, and itching, all of which worsen the quality of life of patients [2,3]. Moreover, DE is a major public health concern with a high incidence [4]; hence, studies on the prevention or treatment of $\mathrm{DE}$ are required.

\footnotetext{
*Correspondence: wblee@kist.re.kr; shjung507@gmail.com

${ }^{1}$ Natural Products Research Center, Korea Institute of Science

and Technology (KIST), Gangneung 25451, South Korea

Full list of author information is available at the end of the article
}

Current treatments for DE primarily depend on artificial tears and cyclosporine A to ameliorate the symptoms and to suppress inflammation $[5,6]$. The mechanism of development of DE is still unclear, but inflammation is known to be a major cause of damage to the ocular surface and cellular damage [7]. Indeed, a clinical study reported that the levels of interleukin (IL)-1, IL-6, IL-8, and tumor necrosis factor-alpha (TNF- $\alpha$ ) are higher in the tears of DE patient tears than in healthy individuals [8]. Thus, a substance capable of regulating inflammatory cytokines is a potentially effective therapeutic agent for DE.

Moreover, persistent chronic inflammation of the eye surface causes loss of goblet [9]. Goblet cells lubricate the surface of the eye during blinking and prevent pathogen penetration. Indeed, mucins produced by goblet cells, ocular mucosal epithelial cells, and the lacrimal gland maintain stabilization of tear film, hydration, and 
lubrication among epithelial cells in the ocular surface $[10,11]$. Therefore, an increase in the goblet cell density may help reconstitute homeostasis in the ocular surface in DE.

Leaves of persimmon (Diospyros kaki), family Ebenaceae, have been used as an ingredient of herbal beverages for centuries in East Asia including Korea, Japan, and China [12, 13]. The leaves of persimmon are beneficial to health and various components of leaves have health promoting effects, including anti-oxidative, antiinflammatory and anti-hypertensive activities [14-17]. Its major compounds are flavonoids such as kaempferol, and quercetin [18]. Flavonoids have potent anti-inflammatory activity in cellular and animal models of various diseases [19-21].

We previously reported that the ethanol extract of $D$. kaki (EEDK) were effective in vivo in an experimental model of dry eye [22]; however, the mechanism of action remains unclear. Therefore, this study aimed to investigate whether goblet cell numbers and inflammatory cytokines are altered after EEDK treatment in vitro and in vivo.

\section{Materials and methods Animals}

The male BALB/c mice were (6 weeks, $20-25$ g) were used in all experiments. Mice were obtained from Central Lab. Animal Inc. (South Korea). Six male mice were housed in individual cage with wood shavings. All mice were allowed ad libitum access to water and a maintenance diet (5L79; ORIENT, Seongnam-si, South Korea) and were maintained on a 12:12-h light-dark cycle with at $23 \pm 0.5^{\circ} \mathrm{C}$ and $10 \%$ humidity.

Animal experiments were conducted in a specific pathogen free (SPF) barrier zone at the Korea Institute of Science and Technology (KIST) Gangneung Institute in accordance with the Association for Research and Vision in Ophthalmology Statement for the Use of Animals in Ophthalmic and Vision Research guidelines. All protocols were reviewed by the Animal Care and Use Committee of KIST (No. 2014-011).

\section{Plant materials}

The ethanol extract of persimmon leaves, D. kaki (EEDK) were extracted with ethanol in an extraction reactor and filtered through filter paper. The combined filtrate was concentrated and dried to obtain EEDK.

\section{Experimental procedure}

For inducing dry eye, a solution of $0.2 \%$ benzalkonium chloride (BAC, Sigma-Aldrich, St. Louis, USA) was instilled on the left eye of the mice [22]. The equal volume of physiological saline was applied to the control group.
A total of 36 mice were randomly divided into 6 groups of 6 animals each: control, DE, $25 \mathrm{mg} / \mathrm{kg}$ EEDK-treated, $50 \mathrm{mg} / \mathrm{kg}$ EEDK-treated, $100 \mathrm{mg} / \mathrm{kg}$ EEDK-treated, and $210 \mathrm{mg} / \mathrm{kg}$ omega-3-treated groups. Omega-3 and EEDK were mixed with $0.5 \%$ aqueous carboxymethylcellulose $(\mathrm{CMC})$ solution. The control and DE groups were given an oral gavage of only $0.5 \% \mathrm{CMC}$ solution.

\section{Fluorescein staining}

The Zoletil ( $1.6 \mu \mathrm{g} / \mathrm{g}$ tiletamine hydrochloride/zolazepam hydrochloride; Virbac Laboratories, USA) and Rompun $(0.05 \mu \mathrm{L} / \mathrm{g}$ xylazine hydrochloride, Bayer HealthCare, UK) were mixed a 1:1 ratio. The mice were anesthetized via intraperitoneal administration of a mixture, as previously reported [22]. Fluorescein staining was performed using a cobalt blue slit lamp after treating corneas with $0.5 \%$ fluorescein solution. The eyelids were closed thrice manually and excess fluorescein (Alcon Laboratories, USA) was wiped from the conjunctival sac.

To measure the fluorescein stained area, fluorescein scoring was performed using the 2007 Dry Eye Work Shop-recommended grading system [23]. Scores of 0 to $4(0=$ no fluorescence, $1=$ slightly punctuate staining, $2=$ punctate staining, $3=$ severe, diffuse staining, $4=$ positive for fluorescein plaque) were assigned depending on the observation.

\section{Periodic acid-Schiff (PAS) staining}

All enucleated mouse eyes were embedded in paraffin and sectioned using a microtome. Sections were incubated with $0.5 \%$ periodic acid solution for $5 \mathrm{~min}$ at room temperature and then washed with distilled water. The sections were immersed in Schiff's Solution for $15 \mathrm{~min}$ and then rinsed in hot running tap water. For counter staining, the sections were stained with hematoxylin and sections were washed again with distilled water. All measurements were performed using a light microscope (Olympus, Tokyo, Japan).

\section{Cell culture}

Human corneal epithelial cells (HCE-T, RIKEN, Japan) were cultured in DMEM/F12 supplemented with 5\% fetal bovine serum (FBS, Gibco, USA), 1X penicillin/ streptomycin, $10 \mathrm{ng} / \mathrm{mL}$ human epithelial growth factor (EGF, Sigma-Aldrich, USA) and 0.5\% dimethyl sulfoxide (DMSO, Sigma-Aldrich, USA). THP1, THP1-XBlue and THP1-Blue-ISG cells (Invitrogen, USA) were cultured in RPMI 1640 medium added with 10\% heat-inactivated FBS, 1X penicillin/streptomycin.

All cells were cultured with $5 \% \mathrm{CO}_{2}$ at $37{ }^{\circ} \mathrm{C}$ in a humidified $\mathrm{CO}_{2}$ culture incubator. All chemicals were dissolved in DMSO (Sigma-Aldrich, USA). 
THP-1 macrophage differentiation and stimulation

THP-1 cells were seeded at $2.0 \times 10^{5}$ cells per well in 12 -well plates. For differentiation into macrophages, the cells were pretreated with $20 \mathrm{ng} / \mathrm{ml}$ phorbol 12-myristate 13-acetate (Sigma-Aldrich, USA) for $48 \mathrm{~h}$. After washing with PBS, cells were pre-treated with 50, 10, and $1 \mu \mathrm{g} / \mathrm{mL}$ EEDK for $1 \mathrm{~h}$, and then stimulated with $100 \mathrm{ng} / \mathrm{mL}$ Pam3-Cys-Ser-Lys4 (Pam3CSK4, Invitrogen, USA) for $6 \mathrm{~h}$.

\section{Quantification of IRF and NF-KB/AP-1 activity}

THP1-Blue-ISG and THP1-XBlue cells are reporter cells that express SEAP under the control of a promoter that can be inducible by transcription factors IRF and NF- $\mathrm{kB} /$ AP-1. Both these reporter cells were pre-treated with EEDK $(1,10$, and $50 \mu \mathrm{g} / \mathrm{mL})$ for $1 \mathrm{~h}$, and then stimulated with Pam3CSK4 $(100 \mathrm{ng} / \mathrm{ml})$ for $18 \mathrm{~h}$. Thereafter, the supernatants were mixed with QUANTI-Blue ${ }^{\mathrm{TM}}$ reagent (InvivoGen, France) according to the manufacturer's instructions. Absorbance was measured at $630 \mathrm{~nm}$ on the multi-plate reader (BioTek Inc., USA).

\section{Total RNA isolation and quantitative real-time RT-PCR analysis}

Total RNA was prepared from harvested cells using the RNeasy Mini kit (QIAGEN, USA). And cDNA was synthesized from total RNA using SuperScript III Reverse Transcriptase (Invitrogen, USA). Then, cDNA was amplified using TaqMan Gene Expression Assay, TaqMan Fast Advanced Master Mix, and the LC480 Detection System (Roche, Switzerland). Target gene expression levels were normalized to glyceraldehyde-3-phosphate dehydrogenase (GAPDH) levels as the internal control. Data analysis and calculations were carried out using the $2^{-\Delta \Delta C T}$ comparative method according to the manufacturer's instructions.

The following forward and reverse primers were used $\left(5^{\prime}\right.$ to $\left.3^{\prime}\right)$ :

\author{
TNF-a_F: GGAGAAGGGTGACCGACTCA. \\ TNF- $\alpha \_R: C T G C C C A G A C T C G G C A A$ \\ IL-6_F: TGCAATAACCACCCCTGACC \\ IL-6_R: TGCGCAGAATGAGATGAGTTG \\ IL-1ß_F: TTTGAGTCTGCCCAGTTCCC \\ IL-1 $\beta$ R: TCAGTTATATCCTGGCCGCC \\ CCL-2_F: CCTTCATTCCCCAAGGGCTC \\ CCL-2_R: GGTTTGCTTGTCCAGGTGGT \\ GAPDH_F: CCATGTTCGTCATGGGTGTG \\ GAPDH_R: GGTGCTAAGCAGTTGGTGGTG
}

\section{Statistical analysis}

All data were assessed using one-way analysis of variance followed by Dunnett's multiple comparisons test for post hoc analysis ( $\mathrm{n}=3$ for each experiments). Data obtained herein are presented as mean \pm standard error of mean values. A statistical probability of $\mathrm{p}<0.05$ was considered significant, and statistical analysis was performed using GraphPad Prism version 7.00 (Graphpad, USA).

\section{Results}

Damage to the ocular surface

To evaluate the damage to the ocular surface, we determined the intensity of fluorescein staining in BACinduced DE in mice (Fig. 1a, b). Before topical treatment of BAC, no significant differences were observed in the control and vehicle-treated corneas (data not shown). In DE groups, corneas were negatively stained with fluorescein (Fig. 1a-ii, b) and their staining intensity was significantly greater than that of the control group (Fig. 1a-i, b). However, treatment of EEDK $(100 \mathrm{mg} / \mathrm{kg}$ and $50 \mathrm{mg} / \mathrm{kg})$ significantly reduced the intensity of negative staining in comparison with the DE group (Fig. 1b). Damage to the corneal surface dose-dependently decreased in EEDKtreated groups (Fig. 1a, b).

Similar effects were observed in the omega- 3 treated group in the positive control (Fig. 1a-iii, b). Moreover, treatment of EEDK $(100 \mathrm{mg} / \mathrm{kg}$ and $50 \mathrm{mg} / \mathrm{kg})$ significantly increased the tear break-up time (Additional file 1: Fig. S1a) and tear volume (Additional file 1: Fig. S1b) in comparison with DE.

These findings suggest that EEDK prevents ocular damage in an experimental DE model.

\section{Assessment of conjunctival goblet cells}

Conjunctival goblet cells were observed after PAS staining (Fig. 2a, b). As shown in Fig. 2b, the number of PAS-positive cells in the conjunctival epithelium was significantly lesser in the DE group than in the control group. Conjunctival goblet cells in the EEDK-treated groups increased in a dose-dependent manner in comparison with the DE group (Fig. 2a-iv-vi, b). Compared with the DE group, the number of goblet cells increased significantly in the $100 \mathrm{mg} / \mathrm{kg}$ EEDK- and $50 \mathrm{mg} / \mathrm{kg}$ EEDK-treated group, similar to that of the positive control, omega-3 groups (Fig. 2a-iii, b). These results suggest that the conjunctival goblet cells are protected by EEDK.

\section{Assessment of inflammatory cytokines}

The mRNA expression of inflammatory cytokines in transformed human corneal epithelial cells (HCE-T) was examined (Fig. 3) in vitro. HCE-T cells were incubated with EEDK prior to induction of Pam3CSK-induced 


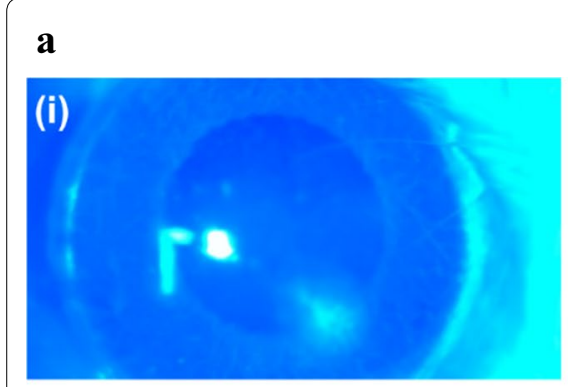

Control

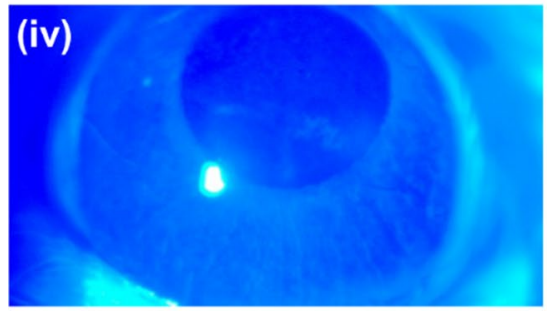

EEDK $100 \mathrm{mg} / \mathrm{kg}$

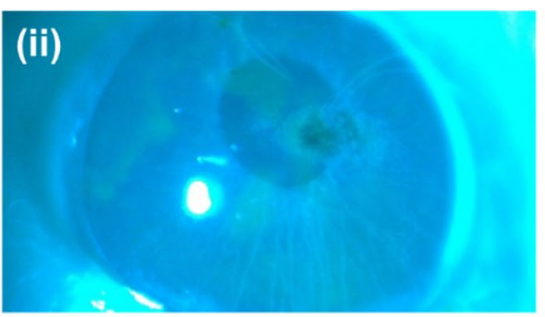

Vehicle (DE)

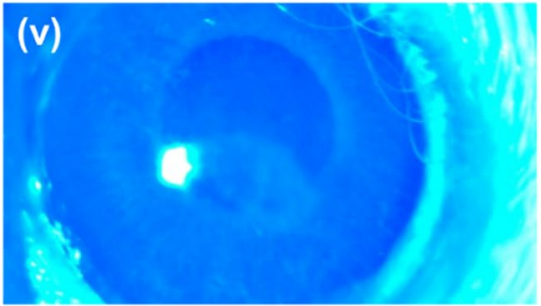

EEDK $50 \mathrm{mg} / \mathrm{kg}$

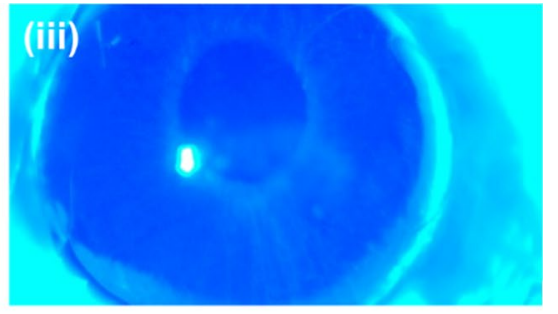

Omega-3 (210 mg/kg)

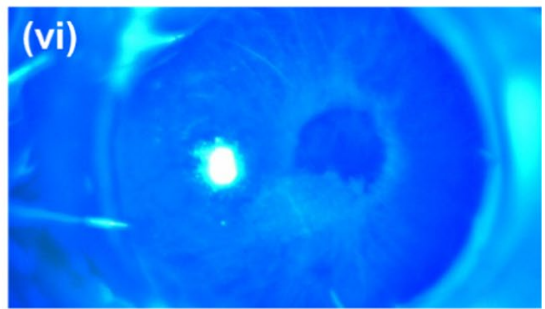

EEDK $25 \mathrm{mg} / \mathrm{kg}$

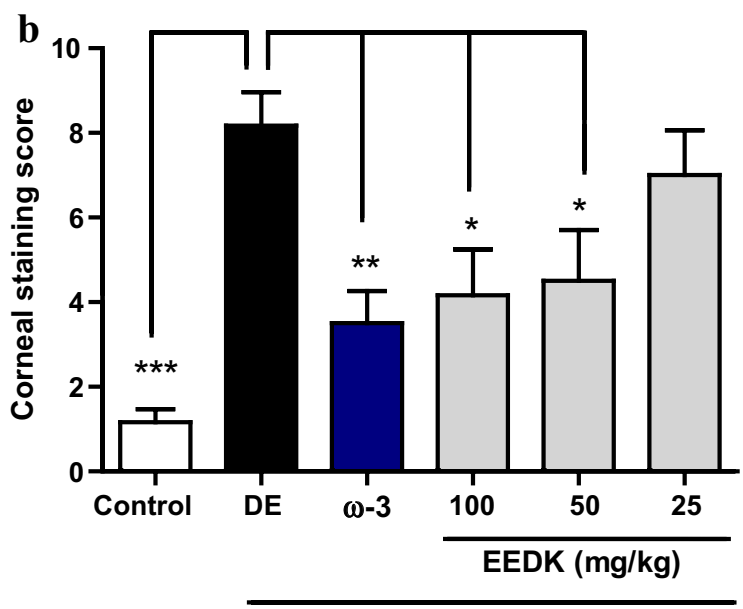

$0.2 \%$ BAC

Fig. 1 Corneal fluorescein staining. a (i) Control (ii) dry eye (DE) (iii) Omega-3 (210 mg/kg) (iv) 100 mg/kg ethanol extract of Diospyros kaki (EEDK)-treated (v) $50 \mathrm{mg} / \mathrm{kg}$ EEDK-treated, and (vi) $25 \mathrm{mg} / \mathrm{kg}$ EEDK-treated mice in all six groups. Omega-3 was used as the positive control. (B) Quantification of corneal fluorescein staining. Experimental values are expressed as mean \pm standard error of the mean values $(n=6$ mice per group, $\left.{ }^{*} p<0.05,{ }^{* *} p<0.01,{ }^{* * *} p<0.001\right)$

inflammation. Treatment of HCE-T cells with $100 \mathrm{ng} /$ mL Pam3CSK4 markedly upregulated pro-inflammatory cytokines including TNF- $\alpha$ (Fig. 3a), IL-6 (Fig. 3b), IL-1 $\beta$ (Fig. 3c), and CCL-2 (Fig. 3d) at the mRNA level. However, treatment with $50 \mu \mathrm{g} / \mathrm{ml}$ EEDK significantly abrogated the upregulation of pro-inflammatory cytokines. CCL-2 mRNA was slightly but not significantly downregulated upon EEDK treatment. Together, these results indicate that EEDK suppresses pro-inflammatory cytokines by targeting Toll-like receptor (TLR).

\section{Assessment of NF-KB and IRF expression}

We examined whether reduced pro-inflammatory cytokines secretion observed in the presence of EEDK was associated with the significantly reduced levels of IRF or NF- $k B$ signaling (Fig. 4). THP-1 cells were pretreated with EEDK at different concentrations and then stimulated with Pam3CSK4. Activation of IRF and NF- $\mathrm{kB}$ signaling remained unchanged in THP-1 cells upon treatment with EEDK. As expected, IRF or NF- $K B$ was potently activated in Pam3CSK4-treated 


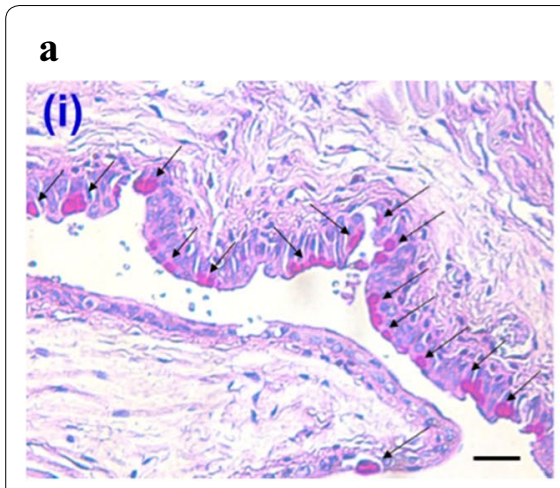

Control

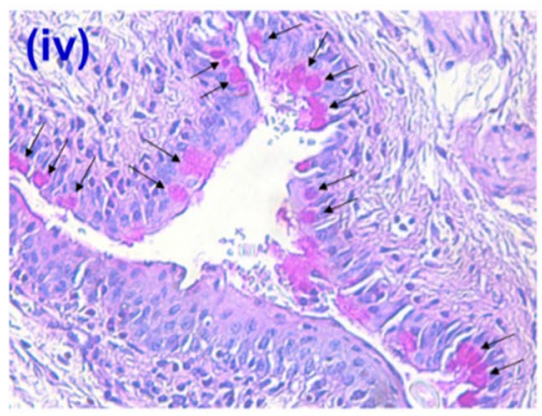

EEDK100 $\mathrm{mg} / \mathrm{kg}$
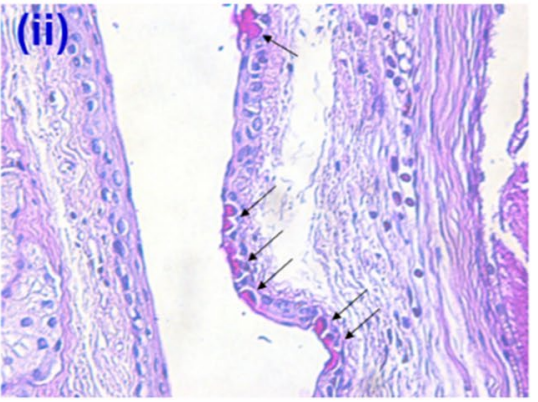

Vehicle (DE)

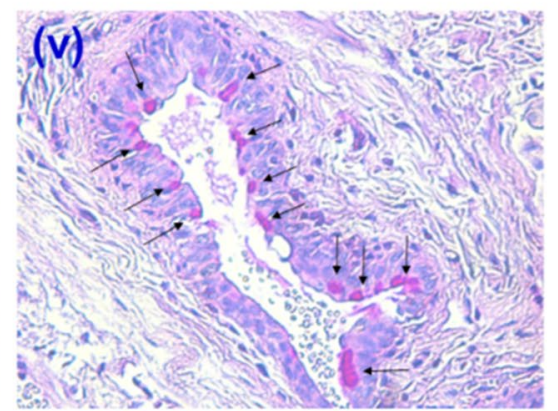

EEDK $50 \mathrm{mg} / \mathrm{kg}$

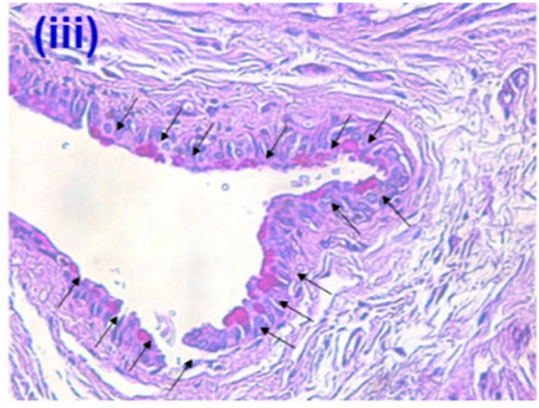

Omega-3 (210 mg/kg)

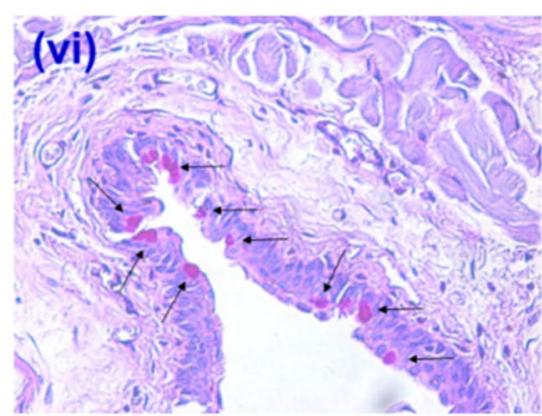

EEDK $25 \mathrm{mg} / \mathrm{kg}$

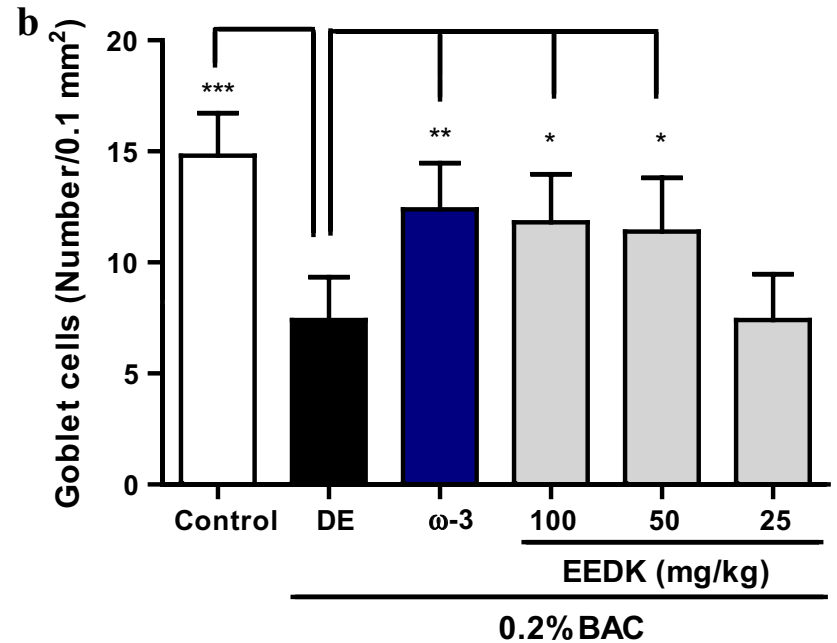

Fig. 2 Periodic Acid-Schiff (PAS) staining of conjunctival tissues. a (i) Control (ii) dry eye (DE) (iii) Omega-3 (210 mg/kg) (iv) $100 \mathrm{mg} / \mathrm{kg}$ ethanol extract of Diospyros kaki (EEDK)-treated (v) $50 \mathrm{mg} / \mathrm{kg}$ EEDK-treated, and (vi) $25 \mathrm{mg} / \mathrm{kg}$ EEDK-treated mice in all six groups. b The number of goblet cells is presented as a mean \pm standard error of the mean value $\left(n=6\right.$ mice per group, $\left.{ }^{*} p<0.05,{ }^{* *} p<0.01,{ }^{* * *} p<0.001\right)$. Arrows indicate PAS-positive cells (Goblet cells), original magnification $(400 \times)$, and scale bars $(50 \mu \mathrm{m})$

cells. However, EEDK effectively reduced IRF activation downstream of TLRs (Fig. 4a), whereas NF- $K B$ signaling activation remained unchanged upon EEDK treatment (Fig. 4b). These data suggest that EEDK regulates Pam3CSK4-induced gene expression in THP-cells through IRF.

\section{Discussion}

DE affects millions of individuals worldwide and causes subtle but constant eye irritation to significant inflammation. Increased inflammatory cytokines in DE have been reported to be associated with loss of goblet cells [9]. We previously reported the protective effects of EEDK on DE 


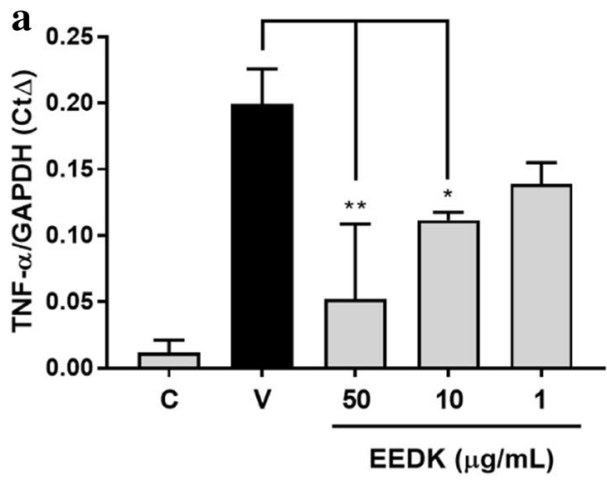

Pam3CSK4 (100 ng/mL)

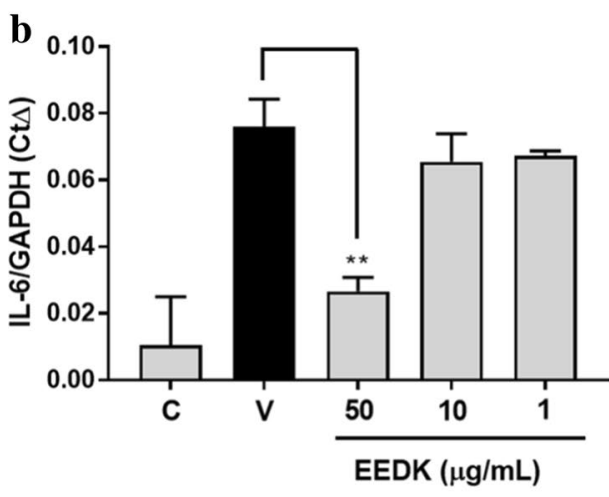

Pam3CSK4 (100 ng/mL)
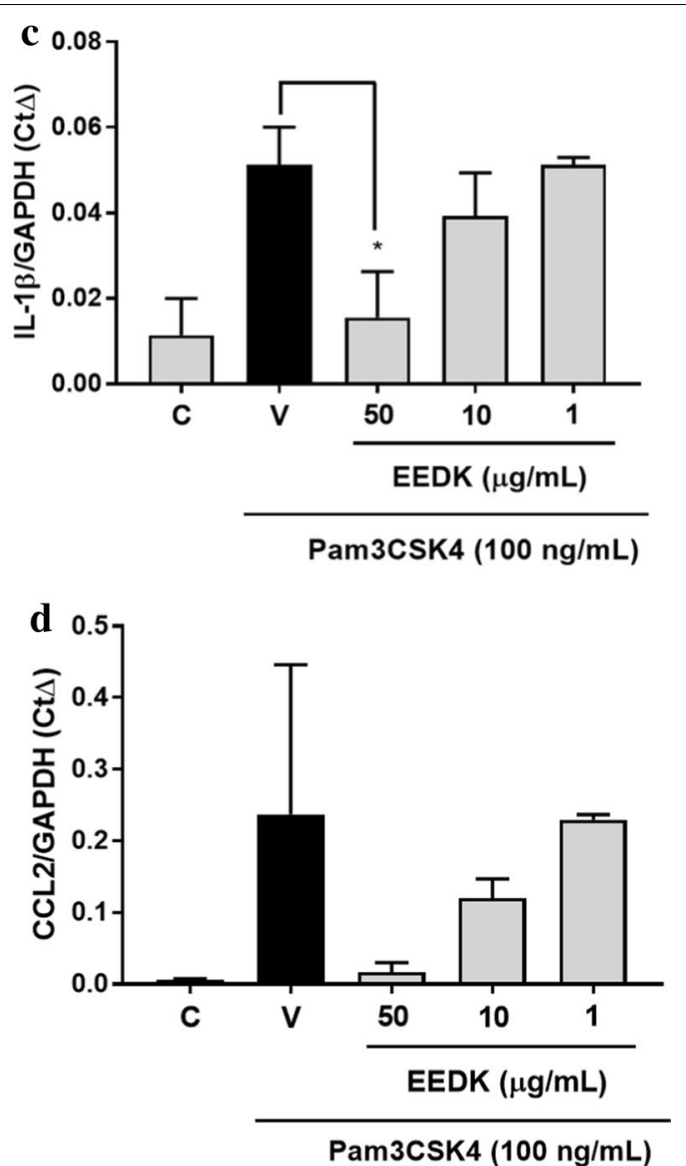

Fig. 3 mRNA levels of pro-inflammatory cytokines. The mRNA level of TNF- $a(\mathbf{a}), I L-6$ (b), IL-1 $\beta$ (c), and CCL-2 (d) induced by Pam3CSK4 in HCE-T cells. Quantification of target mRNA levels relative to GAPDH (internal control). Experimental values are expressed as mean \pm standard error of the mean values from three independent experiments $\left({ }^{*} p<0.05,{ }^{* *} p<0.01\right)$
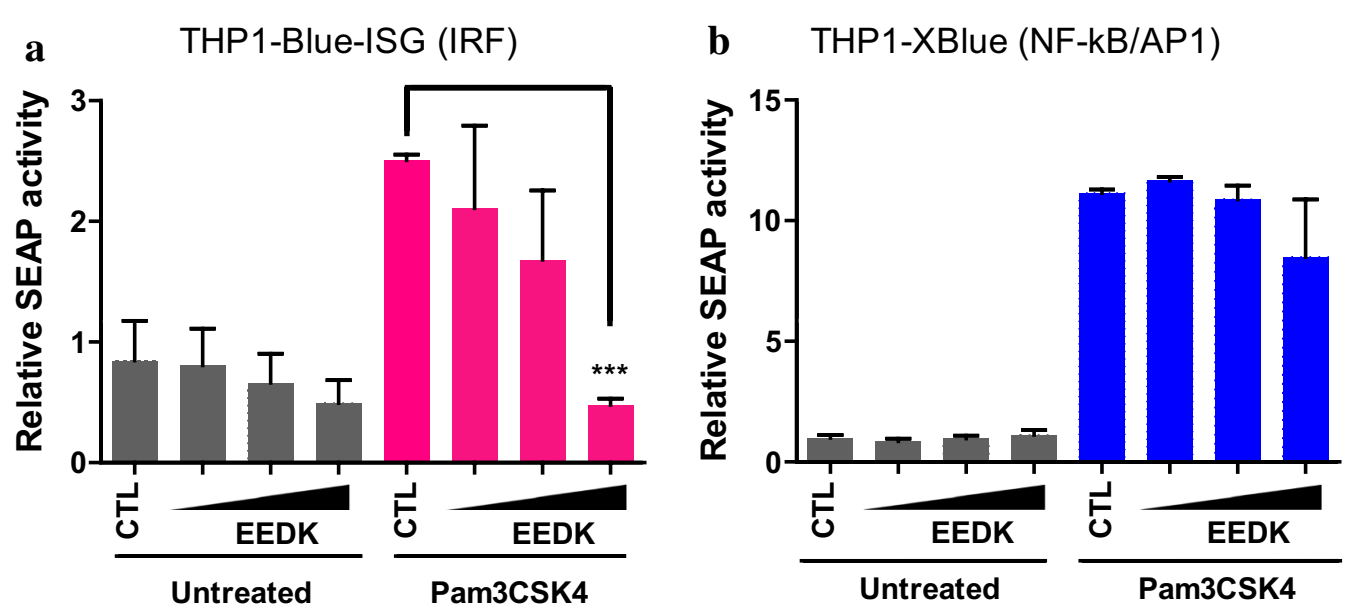

Fig. 4 IRF and NF-KB activity. SEAP reporter assays with THP1-Blue-ISG and THP1-XBlue cells treated with $100 \mathrm{ng} / \mathrm{mL}$ Pam3CSK4 for $18 \mathrm{~h}$. (a) IRF and (b) NF-KB activity. Experimental values are expressed as mean \pm standard error of the mean values from three independent experiments $\left({ }^{* *} p<0.001\right)$ 
in mice [22]; hence, we hypothesized that EEDK would be beneficial in preventing inflammation and reducing the number of conjunctival goblet cells in the DE mouse model. This study is the first to show that EEDK protected BAC-induced DE by reducing the number of goblet cells from decreasing and suppressing inflammatory cytokines.

The BAC-induced mouse model of DE has similar characteristics to those of humans including damage of the corneal surface, instability of the tear film, inflammation, reduction of the conjunctival goblet cells, and epithelial cell death [24]. Topical instillation of BAC increased the intensity of fluorescein staining, indicating corneal damage and tear film instability $[25,26]$. Furthermore, a BACinduced mouse model of DE was successfully established in this study with increased fluorescein and a reduced number of conjunctival goblet cell numbers (Figs. 1 and 2). Omega-3 fatty acids help reverse DE-associated corneal epithelial damage [27]; hence, in this study, they significantly reduced corneal damage and increased goblet cell number. The present result show that EEDK significantly reduced corneal damage and increased conjunctival goblet cells, similar to the Omega-3 treated effects (Figs. 1 and 2).

Conjunctival goblet cells play an important role in the formation and stability of tear film [28]. Conjunctival goblet cells produce mucins that hydrate and lubricate epithelial cells of the eye surface $[10,11]$. The relevant gene expressed in conjunctival goblet cells is the gelforming MUC5AC, which contributes to the viscoelastic properties of mucus for protection against pathogens [29]. Moreover, MUC5AC is regulated by inflammatory mediators [29]. Our study shows that EEDK treatment protects conjunctival goblet cells against BAC-induced DE (Fig. 2), suggesting that EEDK treatment potentially involves MUC5AC expression to maintain the stability of tear film on the eye surface.

The present results indicate that EEDK protects goblet cells (Fig. 2) and the ocular surface (Fig. 1) in an experimental mouse model of DE. We previously isolated and identified EEDK and isolated flavonoid compounds including quercetin-3-O- $\beta$-galactoside, quercetin-3$O$ - $\beta$-glucoside, $\quad$ quercetin-3-O- $\beta$-2"-galloylglucoside, kaempferol-3-O- $\beta$-galactoside, kaempferol-3-O- $\beta$ glucoside, kaempferol -3-O- $\beta-2$ "-galloylglucoside, quercetin, and kaempferol [30]. Flavonoids have a structural backbone of C6-C3-C6 of two aromatic ring (called the A- and B-rings) connected by a $3 \mathrm{C}$ chain, typically organized as an oxygenated heterocyclic ring [31]. Flavonoids exert similar effects to those of anti-inflammatory drugs [32]. Moreover, these compounds diminish the activity of pro-inflammatory cytokines and mediators in various studies [33, 34]. We speculated that suppression of inflammation by EEDK might help protect goblet cells. However, flavonoids have potential effects on mucin 5AC (MU5AC) expression in airway epithelial cells [35]. Therefore, further research is needed to investigate how EEDK works on goblet cell protection and mucin in DE.

Pro-inflammatory cytokines reduce conjunctival goblet cells, leading to instability of the tear film [36]. TLRs expressed on the ocular surface cells bind to various microbial components including bacterial lipopeptide (a TLR2 ligand), lipopolysaccharide (a TLR4 ligand), and CpG-rich DNA (a TLR9 ligand) [37], resulting in a TLR2-, TLR4-, and TLR9-mediated signaling cascade leading to NF- $\mathrm{kB}$ and IRF to cellular nucleus, followed by binding to target genes [38-40]. Kumar A et al. have shown that TLR2 is activated in the cornea by Grampositive bacterial molecules that cause the secretion of pro-inflammatory cytokines by corneal epithelial cells via NF- $\kappa B$ activation $[41,42]$. Since Pam3CSK4 is a synthetic triacylated lipopeptide agonist as a Gram-positive molecule mimic with TLR2 signaling activation [43, 44], we evaluated the anti-inflammatory effects of EEDK. Furthermore, the synthetic bacterial lipopeptide Pam3CSK4 is an effective activator of the NF- $k B$ and IRF pathway. TLR-induced NF- $k B$ and IRF signaling mediates the expression of pro-inflammatory factors including TNF$\alpha$, IL-1 $\beta$, IL- 6 , IL-8, C-C motif ligand-5 (CCL-5), and monocyte chemoattractant protein-1 (MCP-1) [45-47].

To examine whether EEDK suppresses the secretion of pro-inflammatory cytokines evoked by Pam3CSK4, we assessed mRNA levels of these genes in HCE-T cells. The present results show that Pam3CSK4 significantly increases TNF- $\alpha$, IL-6, IL-1 $\beta$, and CCL-2 (Fig. 3) at the mRNA level. Upon EEDK treatment, mRNA levels of them (Fig. 3a-d) were lower in comparison with vehicle treatment. Nevertheless, expression of CCL-2 in EEDK treatment did not show a significant difference compared to the control (Fig. 3d).

In corneal epithelial cells TLR-2 signaling causes the activation of NF- $\mathrm{KB}$ and IRF [48, 49]. We assessed the regulatory effect of EEDK on IRF and NF- $\mathrm{kB}$ activation using gene reporter assays in THP-1 cells. The present results show that EEDK significantly suppressed IRF downstream of TLRs, while NF-kB signaling activation remained unchanged upon EEDK treatment (Fig. 4). Moreover, in human corneal epithelial cells, IRF-1 levels increased after a bacterial challenge, for example, Pseudomonas aeruginosa, which played an important role in MHC class II gene expression in macrophages [50]. However, interestingly, flavonoids selectively induce IRF-1 degradation in intestinal epithelial cells [51] in which there are many flavonoids in the EEDK. Thus, we speculate that the effects of EEDK on suppressing IRF may be related to these components. 
In conclusion, this study shows that EEDK treatment prevents DE in a mouse model, probably by increasing the goblet cell density and anti-inflammatory effects by reducing IRF activation downstream of TLRs. EEDK treatment is a potentially attractive strategy for preventing and treating DE.

\section{Supplementary information}

Supplementary information accompanies this paper at https://doi. org/10.1186/s13765-020-00529-7.

Additional file 1: Fig. S1. Clinical ocular assessments. a Tear break-up time (BUT) and $\mathbf{b}$ Schirmer's test (Tear volume). Experimental values are expressed as the mean \pm standard error of the mean (SEM) $(n=6$ per group, $\left.{ }^{*} p<0.05,{ }^{* *} p<0.01,{ }^{* * *} p<0.001\right)$.

\section{Abbreviations}

BAC: Benzalkonium chloride; CMC: Carboxymethylcellulose; DE: Dry eye; DMSO: Dimethyl sulfoxide; EEDK: Ethanol extract of D. kaki; HCE-T: Human corneal epithelial cells; GAPDH: Glyceraldehyde-3-phosphate dehydrogenase; IL: Interleukin; Pam3CSK4: Pam3-Cys-Ser-Lys4; PAS: Periodic acid-schiff; TNF-a: Tumor necrosis factor-alpha.

\section{Authors' contributions}

KK designed the experimental approach, coordinated the project, interpreted the data and wrote the manuscript. WBL designed the experimental approach and wrote the manuscript; TKK performed sample preparation and data collection; $\mathrm{CHL}$ and SJY analyzed the clinical data; CYL reviewed and edited manuscript. SHJ supervised the project and provided financial support. All authors helped design the study, provided editorial comments and assistance, and have read and approved the submitted manuscript. All authors read and approved the final manuscript.

\section{Funding}

This study was financially supported by a Grant (Code No. 2Z05310, 2Z06260) from Korea Institute of Science and Technology (KIST) of South Korea.

\section{Availability of data and materials}

The datasets used and/or analyzed during the current study are available from the corresponding author on reasonable request.

\section{Competing interests}

The authors have declared no competing financial or commercial interests.

\section{Author details}

${ }^{1}$ Natural Products Research Center, Korea Institute of Science and Technology (KIST), Gangneung 25451, South Korea. ${ }^{2}$ Division of Bio-Medical Science \&Technology, KIST School, Korea University of Science and Technology (UST), Seoul 02792, South Korea. ${ }^{3}$ Department of Ophthalmology, University of Ulsan, Gangneung Asan Hospital, Gangneung, South Korea. ${ }^{4}$ J's Retinal Clinic, 2nd Floor, Grand Tower Building, Gangneung 25531, South Korea.

${ }^{5}$ Department of Food Science, Cornell University, Ithaca 14850, USA.

Received: 29 June 2020 Accepted: 8 August 2020

Published online: 13 August 2020

\section{References}

1. Craig JP, Nichols KK, Akpek EK, Caffery B, Dua HS, Joo CK, Liu Z, Nelson JD, Nichols JJ, Tsubota K, Stapleton F (2017) TFOS DEWS II Definition and classification report. Ocul Surf 15:276-283. https://doi.org/10.1016/j. jtos.2017.05.008

2. Pflugfelder SC, Solomon A, Stern ME (2000) The diagnosis and management of dry eye: a twenty-five-year review. Cornea 19:644-649
3. Xu KP, Yagi Y, Tsubota K (1996) Decrease in corneal sensitivity and change in tear function in dry eye. Cornea 15:235-239

4. Aggarwal S. and Galor A. (2018) What's new in dry eye disease diagnosis? Current advances and challenges. F1000Res 7:https://doi.org/10.12688/ f1000research.16468.1

5. Whitcup SM, Chan CC, Luyo DA, Bo P, Li Q (1996) Topical cyclosporine inhibits mast cell-mediated conjunctivitis. Invest Ophthalmol Vis Sci 37:2686-2693

6. Yuksel B, Bozdag B, Acar M, Topaloglu E (2010) Evaluation of the effect of topical cyclosporine A with impression cytology in dry eye patients. Eur J Ophthalmol 20:675-679

7. Wakamatsu TH, Dogru M, Tsubota K (2008) Tearful relations: oxidative stress, inflammation and eye diseases. Arq Bras Oftalmol 71:72-79

8. Zhao H, Li Q, Ye M, Yu J (2018) Tear luminex analysis in dry eye patients. Med Sci Monit 24:7595-7602. https://doi.org/10.12659/MSM.912010

9. Baudouin C (2001) The pathology of dry eye. Surv Ophthalmol 45(Suppl 2):S211-S220

10. Stephens DN, McNamara NA (2015) Altered mucin and glycoprotein expression in dry eye disease. Optom Vis Sci 92:931-938. https://doi. org/10.1097/Opx.0000000000000664

11. Govindarajan B, Gipson IK (2010) Membrane-tethered mucins have multiple functions on the ocular surface. Exp Eye Res 90:655-663. https:// doi.org/10.1016/j.exer.2010.02.014

12. Yaqub S, Farooq U, Shafi A, Akram K, Murtaza MA, Kausar T, Siddique F (2016) Chemistry and functionality of bioactive compounds present in Persimmon. J Chem. https://doi.org/10.1155/2016/3424025

13. Sakanaka S, Tachibana Y, Okada Y (2005) Preparation and antioxidant properties of extracts of Japanese persimmon leaf tea (kakinoha-cha). Food Chem 89:569-575. https://doi.org/10.1016/j.foodchem.2004.03.013

14. Sun L, Zhang J, Lu X, Zhang L, Zhang Y (2011) Evaluation to the antioxidant activity of total flavonoids extract from persimmon (Diospyros kaki L.) leaves. Food Chem Toxicol 49:2689-2696. https://doi.org/10.1016/j. fct.2011.07.042

15. Kawakami K, Aketa S, Sakai H, Watanabe Y, Nishida H, Hirayama M (2011) Antihypertensive and vasorelaxant effects of water-soluble proanthocyanidins from persimmon leaf tea in spontaneously hypertensive rats. Biosci Biotechnol Biochem 75:1435-1439. https://doi.org/10.1271/bbb.100926

16. Hossain A, Moon HK, Kim JK (2018) Antioxidant properties of Korean major persimmon (Diospyros kaki) leaves. Food Sci Biotechnol 27:177184. https://doi.org/10.1007/s10068-017-0195-y

17. Sancheti S, Sancheti S, Bafna M, Lee SH, Seo SY (2011) Persimmon leaf (Diospyros kaki), a potent alpha-glucosidase inhibitor and antioxidant: alleviation of postprandial hyperglycemia in normal and diabetic rats. J Med Plant Res 5:1652-1658

18. Xie C, Xie Z, Xu X, Yang D (2015) Persimmon (Diospyros kaki L.) leaves: a review on traditional uses, phytochemistry and pharmacological properties. J Ethnopharmacol 163:229-240. https://doi.org/10.1016/j. jep.2015.01.007

19. Kumar S, Pandey AK (2013) Chemistry and biological activities of flavonoids: an overview. Sci World J 2013:162750. https://doi. org/10.1155/2013/162750

20. Pan MH, Lai CS, Ho CT (2010) Anti-inflammatory activity of natural dietary flavonoids. Food Funct 1:15-31. https://doi.org/10.1039/c0fo00103a

21. Yoon JH, Baek SJ (2005) Molecular targets of dietary polyphenols with anti-inflammatory properties. Yonsei Med J 46:585-596. https://doi. org/10.3349/ymj.2005.46.5.585

22. Kim KA, Hyun LC, Jung SH, Yang SJ (2016) The leaves of Diospyros kaki exert beneficial effects on a benzalkonium chloride-induced murine dry eye model. Mol Vis 22:284-293

23. Zhang Z, Yang WZ, Zhu ZZ, Hu QQ, Chen YF, He H, Chen YX, Liu ZG (2014) Therapeutic effects of topical doxycycline in a benzalkonium chlorideinduced mouse dry eye model. Invest Ophthalmol Vis Sci 55:2963-2974. https://doi.org/10.1167/iovs.13-13577

24. Xiong C, Chen D, Liu J, Liu B, Li N, Zhou Y, Liang X, Ma P, Ye C, Ge J, Wang Z (2008) A rabbit dry eye model induced by topical medication of a preservative benzalkonium chloride. Invest Ophthalmol Vis Sci 49:1850-1856. https://doi.org/10.1167/iovs.07-0720

25. Lin Z, Liu X, Zhou T, Wang Y, Bai L, He H, Liu Z (2011) A mouse dry eye model induced by topical administration of benzalkonium chloride. Mol Vis 17:257-264 
26. Chen W, Li Z, Hu J, Zhang Z, Chen L, Chen Y, Liu Z (2011) Corneal alternations induced by topical application of benzalkonium chloride in rabbit. PLoS ONE 6:e26103. https://doi.org/10.1371/journal.pone.0026103

27. Cortina MS, Bazan HE (2011) Docosahexaenoic acid, protectins and dry eye. Curr Opin Clin Nutr Metab Care 14:132-137. https://doi.org/10.1097/ MCO.0b013e328342bb1a

28. Dartt DA, Masli S (2014) Conjunctival epithelial and goblet cell function in chronic inflammation and ocular allergic inflammation. Curr Opin Allergy Clin Immunol 14:464-470. https://doi.org/10.1097/ACI.000000000000009 8

29. Ostedgaard LS, Moninger TO, MCMenimen JD, Sawin NM, Parker CP, Thornell IM, Powers LS, Gansemer ND, Bouzek DC, Cook DP, Meyerholz DK, Abou AMH, Stoltz DA, Welsh MJ (2017) Gel-forming mucins form distinct morphologic structures in airways. Proc Natl Acad Sci 114(26):6842-6847

30. Kim KA, Kang SW, Ahn HR, Song Y, Yang SJ, Jung SH (2015) Leaves of Persimmon (Diospyros kaki Thunb.) ameliorate N-methyl-N-nitrosourea (MNU)-induced retinal degeneration in mice. J Agric Food Chem 63:7750-7759. https://doi.org/10.1021/acs.jafc.5b02578

31. Halbwirth $\mathrm{H}$ (2010) The creation and physiological relevance of divergent hydroxylation patterns in the flavonoid pathway. Int J Mol Sci 11:595-621. https://doi.org/10.3390/ijms11020595

32. Lopez-Posadas R, Ballester I, Mascaraque C, Suarez MD, Zarzuelo A, Martinez-Augustin O, Sanchez de Medina F (2010) Flavonoids exert distinct modulatory actions on cyclooxygenase 2 and NF-kappaB in an intestinal epithelial cell line (IEC18). Br J Pharmacol 160:1714-1726. https ://doi.org/10.1111/j.1476-5381.2010.00827.x

33. Nair MP, Mahajan S, Reynolds JL, Aalinkeel R, Nair H, Schwartz SA, Kandaswami C (2006) The flavonoid quercetin inhibits proinflammatory cytokine (tumor necrosis factor alpha) gene expression in normal peripheral blood mononuclear cells via modulation of the NF-kappa beta system. Clin Vaccine Immunol 13:319-328. https://doi.org/10.1128/CVI.13.3.319-328.2006

34. Cho SY, Park SJ, Kwon MJ, Jeong TS, Bok SH, Choi WY, Jeong WI, Ryu SY, Do SH, Lee CS, Song JC, Jeong KS (2003) Quercetin suppresses proinflammatory cytokines production through MAP kinases and NF-kappaB pathway in lipopolysaccharide-stimulated macrophage. Mol Cell Biochem 243:153-160

35. Liou CJ, Huang WC (2017) Casticin inhibits interleukin-1beta-induced ICAM-1 and MUC5AC expression by blocking NF-kappaB, PI3K-Akt, and MAPK signaling in human lung epithelial cells. Oncotarget 8:101175101188. https://doi.org/10.18632/oncotarget.20933

36. Zhang X, Qu Y, He X, Ou S, Bu J, Jia C, Wang J, Wu H, Liu Z, Li W (2017) Dry eye management: targeting the ocular surface microenvironment. Int J Mol Sci 18(7):1398

37. Pearlman E, Johnson A, Adhikary G, Sun Y, Chinnery HR, Fox T, Kester M, Mcmenamin PG (2008) Toll-like receptors at the ocular surface. Ocul Surf 6:108-116. https://doi.org/10.1016/S1542-0124(12)70279-3

38. Troutman TD, Bazan JF, Pasare C (2012) Toll-like receptors, signaling adapters and regulation of the pro-inflammatory response by PI3K. Cell Cycle 11:3559-3567. https://doi.org/10.4161/cc.21572
39. Makela SM, Strengell M, Pietila TE, Osterlund P, Julkunen I (2009) Multiple signaling pathways contribute to synergistic TLR ligand-dependent cytokine gene expression in human monocyte-derived macrophages and dendritic cells. J Leukoc Biol 85:664-672. https://doi.org/10.1189/ jlb.0808503

40. Pang Z, Junkins RD, Raudonis R, MacNeil AJ, McCormick C, Cheng Z, Lin TJ (2018) Regulator of calcineurin 1 differentially regulates TLR-dependent MyD88 and TRIF signaling pathways. PLoS ONE 13:e0197491. https://doi. org/10.1371/journal.pone.0197491

41. Oosenbrug T, van de Graaff MJ, Ressing ME, van Kasteren SI (2017) Chemical tools for studying signaling dynamics. Cell Chem Biol. 24:801-812. https://doi.org/10.1016/j.chembiol.2017.05.022

42. Kumar A, Yu FS (2006) Toll-like receptors and corneal innate immunity. Curr Mol Med 6:327-337. https://doi.org/10.2174/156652406776894572

43. Li Q, Kumar A, Gui JF, Yu FSX (2008) Staphylococcus aureus lipoproteins trigger human corneal epithelial innate response through toll-like receptor-2. Microb Pathog 44:426-434. https://doi.org/10.1016/j.micpa th.2007.11.006

44. Kumar A, Zhang J, Yu FSX (2004) Innate immune response of corneal epithelial cells to Staphylococcus aureus infection: role of peptidoglycan in stimulating proinflammatory cytokine secretion. Invest Ophthalmol Vis Sci 45:3513-3522. https://doi.org/10.1167/iovs.04-0467

45. Lee SH, Park SR (2018) Toll-like receptor $1 / 2$ agonist Pam3CSK4 suppresses lipopolysaccharide-driven IgG1 production while enhancing IgG2a production by B cells. Immune Netw. https://doi.org/10.4110/in.2018.18. e10

46. Fitzgerald KA (2003) LPS-TLR4 signaling to IRF-3/7 and NF-Kappa B involves the toll adapters TRAM and TRIF. J Exp Med 198:1043

47. Newton K, Dixit VM (2012) Signaling in innate immunity and inflammation. Cold Spring Harb Perspect Biol. https://doi.org/10.1101/cshperspec t.a006049

48. Yu FSX, Hazlett LD (2006) Toll-like receptors and the eye. Invest Ophthalmol Vis Sci 47:1255-1263. https://doi.org/10.1167/iovs.05-0956

49. Courson J, Lema C, Redfern RL (2015) The role of Toll-like receptors in experimental dry eye inflammation. Invest Ophthalmol Vis Sci 56:3049

50. Kessal K, Liang H, Rabut G, Daull P, Garrigue JS, Docquier M, Melik Parsadaniantz S, Baudouin C, Brignole-Baudouin F (2018) Conjunctival inflammatory gene expression profiling in dry eye disease: correlations with HLA-DRA and HLA-DRB1. Front Immunol 9:2271. https://doi. org/10.3389/fimmu.2018.02271

51. Ruiz PA, Haller D (2006) Functional diversity of flavonoids in the inhibition of the proinflammatory NF-kappaB, IRF, and Akt signaling pathways in murine intestinal epithelial cells. J Nutr 136:664-671. https://doi. org/10.1093/jn/136.3.664

\section{Publisher's Note}

Springer Nature remains neutral with regard to jurisdictional claims in published maps and institutional affiliations.

\section{Submit your manuscript to a SpringerOpen ${ }^{\circ}$ journal and benefit from:}

- Convenient online submission

- Rigorous peer review

- Open access: articles freely available online

- High visibility within the field

- Retaining the copyright to your article

Submit your next manuscript at springeropen.com 